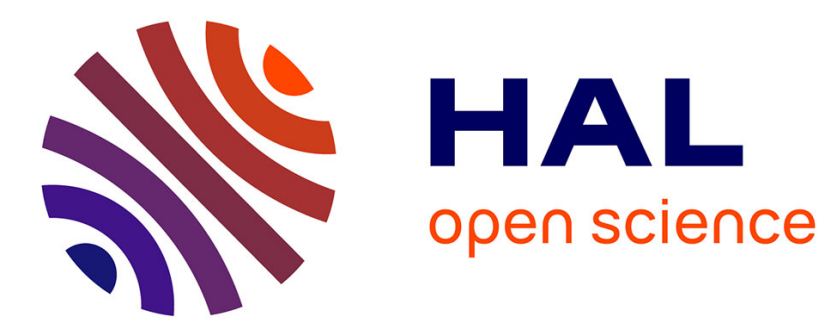

\title{
On Extraordinary Neurosis: An Introduction \\ Renaud Evrard
}

\section{To cite this version:}

Renaud Evrard. On Extraordinary Neurosis: An Introduction. Recherches en psychanalyse, 2013, Sujet, subjectivités et pratiques de corps dans le monde contemporain / Subject, Subjectivities, and Practices of the Body in the Contemporary World, 15, pp.78a-86a. 10.3917/rep.015.0078a . halshs02137214

\section{HAL Id: halshs-02137214 https://shs.hal.science/halshs-02137214}

Submitted on 22 May 2019

HAL is a multi-disciplinary open access archive for the deposit and dissemination of scientific research documents, whether they are published or not. The documents may come from teaching and research institutions in France or abroad, or from public or private research centers.
L'archive ouverte pluridisciplinaire HAL, est destinée au dépôt et à la diffusion de documents scientifiques de niveau recherche, publiés ou non, émanant des établissements d'enseignement et de recherche français ou étrangers, des laboratoires publics ou privés. 


\section{1 - Introduction}

$\mathrm{R}$ ecent research into the notion of "ordinary psychosis" has shown the considerable fecundity and pertinence of the structuralist conception of psychosis (Miller, 1999, 2009). The first conception of Lacan's psychoses drew on the "extraordinary psychosis" of President Schreber, with a clinical picture that included above all hallucinations and delusions. The second conception, based around the Borromean knots and the sinthome, concerned Joyce. Lacan showed that Joyce was not delusional in everyday life, but his psychotic structure could be read in his writings and his literary ambitions. This other form of psychosis, which presents a predominance of discrete signs, calls into question the relationship between psychosis and social adaptation and the possibility for the psychosé of avoiding a triggering by forging himself a sinthome that will supplement his deprivation of the paternal function (Lévy, 2012; Pellion, 2009; Hoffman, 2009).

2 Furthermore, we can accept a large part of Freud's heritage as a description of "ordinary neurosis", that is to say, clinical pictures of subjects who are structured on the side of neurosis, who function in the social field, but who are not endowed with a "psychopathology of everyday life" that is liable to worsen. Except that Freud collected, as did many clinicians of his time, numerous examples of hysterical neuroses that were subject to hallucinations and delusions. The Studies on Hysteria by Breuer and Freud (1895) put the "grand hysterics" on the stage: with the exception of Elisabeth von R., all of them have hallucinations and other phenomena generally associated with psychosis: Anna O. has visual hallucinations of black snakes and has disturbances of speech (which include the exclusive use of foreign languages); Emmy von N. has frightening hallucinations of animals and corpses and ultimately displays delusion; Miss Lucy R. has olfactory hallucinations; Katherina repeatedly hallucinates a frightening head.

3 Out of concern for symmetry, might it not be possible to develop a reflection on a continuum between "ordinary neurosis" and "extraordinary neurosis", and the transitions that offer an explanation for these different manifestations within the same psychical structure? This examination is reminiscent of other, older discussions, much as though we were inheriting a "leftover" that has not been metabolized by dynamic psychiatry.

\section{2 - "Extraordinary Neuroses" in the Nineteenth Century}

4The term "extraordinary neurosis" was at the centre of discussions held by the Medical and Psychological Society of Paris from 1857 onwards. Pierre Janet was critical of the adjective "extraordinary" which merely called to mind the former ignorance of the medical establishment in the face of neuroses, "as though it were reasonable to employ this word for the examination of natural phenomena" (Janet, 1905 / 2008, p. 372). According to one historian, these "extraordinary neuroses" designate "para-psychological phenomena" (Biéder, 2002, p. 727). In actual fact the issue would seem to be more complex. But it cannot be denied that the extraordinary neuroses constitute a leftover from the time of the Lucid Somnambulism of the Marquis de Puységur which was developed during this "low period" in order for magnetic healing to be included at the Academy of Medicine, prior to its re-appropriation in the form of a watered down "medical hypnosis" (Méheust, 1999).

5 In the works of Despine (1880) and Billet (1874), as well as in the cases discussed at the Medical Psychological Society (on 16 and 30 November, 1857; on 14 and 28 December 1857; and finally on 25 January 1858 and 22 February 1958), we can see a set coming to light, which resembles a "catch all" category, gathering together what were still marginal questions related to hysteria, ecstatic states, convulsive fits, hyperesthesia, lucidity, split personalities, animal magnetism, sleep walking, mental suggestion, catalepsy and cutaneous anesthesia. The cases that were presented were often those of young women who had hallucinations and delusions in the course of transitory fits. 
6The first observation came from Dr Lunier (1958), who presented Lise, a fourteen year old girl whose menstruations were followed by "fits". In "magnetizing" the young girl, Dr Lunier obtained facts of lucidity whose authenticity he defended before the audience of the Medical Psychological Society. He affirmed that he had been able to integrate these events into the field of psychopathology:

I admit, since I have observed, the existence in some young subjects of an aptitude to be influenced by other people in such a way that they can develop within themselves a special state that is in every respect similar to that of natural sleep walking. I admit that these subjects can, in their waking state or in a state of somnambulic sleep (whether spontaneous or provoked), present us with phenomena that, in the current state of science, we cannot comprehend and can scarcely better explain, but whose existence it is simply not possible to deny.

I consider these facts to be pathological, and consequently I consider them as falling within our scope of study. (Lunier, 1958, p. 232; his italics)

8 The discussion went on to a reveal an audience divided between enthusiasm and defiance. Moreau de Tours warned the Society against publishing the discussion, since to his mind it would open up a breech in the scientific authority of the Society, which would be compromised by making people believe that all the strange facts of animal magnetism were possible.

9 Further observations accumulated during the next sessions. The debates that followed anticipated the psychical research at the end of the nineteenth century: a legitimacy at the level of its experimentation but which met difficulty in obtaining evidence, which was followed by doctoring of results, an influence of the beliefs and reputations of the subjects, along with the place of psychopathology. After a debate which concluded that the medium Douglas D. Home had been caught in the act of deception, the discussion was to come to an abrupt halt on the proposition from Baillarger (Cerise, 1858, p. 312) who stood in opposition to Parchappe, Peisse, Archambault and Brierre de Boismont. According to Alfred Maury, the discussion had been "wrong to draw on so long" (Maury in Cerise, 1858, p. 311), notably because it was soliciting the creation of a commission whose mission would be to verify some of the facts in consultation with "gifted" subjects. [1][1]Doctor Motet (1861) was none the less to be allowed to present...

10This closure concluded with a message from the founder of the Medical Psychological Society and cofounder of the Annales Médico Psychologiques, Laurent Cerise, in which he opened up further lines of enquiry, which unfortunately were prematurely nipped in the bud in the same way:

1. A first line of enquiry, which is easily assimilated into anomalistic psychology (Cardeña, Lynn \& Krippner, 2000; Holt, Simmonds-Moore, Luke \& French, 2012; Kramer, Bauer \& Hövelmann, 2012), was the pathological and therapeutic study of extraordinary phenomena in and of themselves, even when they are only extraordinary in appearance (Cerise, 1858, p. 310).

2. A second line of enquiry is the use of the therapeutic means constituted by hypnosis, which at that time he calls somniloquence, as a way of curing neurotic disturbances by taking distance from the fascination for "miracles of lucidity" which do not bring any further benefits on the clinical plane (Cerise, 1858, p. 309).

Thereafter, these two lines of enquiry were to be effectively uncoupled, even though the cases then being presented, and a number of those that follow, mix neuroses with "somnambulic" states and paranormality. This is particularly visible in Pierre Janet who, from the time of his thesis on "psychological automatism" (1889), was to reduce systematically his observations on "mediums", "the possessed" and other "somnambulists" to pathological processes that could be manipulated by hypnosis. Several decades after the observations at the Medical Psychological Society, Janet was heir to these observations of neuroses which he described as serious forms of hysteria accompanied by hallucinations, by delusions, and by personality dissociation. In France, cases such as those described by Janet would go on to vanish from the clinical literature as of 1910 for various reasons which have already been analyzed by Maleval (1981). Meanwhile, this heritage endured on foreign soil in a phenomenological form rather than a clinical one, being more or less a borrowing from its supernatural original (Prince, 1905; Mitchell, 1922; Casey, 1940).

11 Whereas the concept of dissociation, which was introduced by none other than Janet himself, came to shed light on the crises of personality that form part of the clinical picture of "extraordinary neuroses", the successive versions of nosography simply blurred the boundaries once more (Garrabé, 1999). Indeed, whereas Viallard, author of the first complete French translation of Bleuler's book on the classificatory grouping of schizophrenias (1911), translated Splatung as scission ["split"], it was the term "dissociation" that came to be adopted by everyday use, creating some confusion with the works of Janet and others (Revez \& Rossel, 2007) and closing the door on the non pathological dissociation which was to be pursued on the other side of the Atlantic (Casey, 
1940), even going on to be included in the Diagnostic and Statistical Manual (Spitzer, Barnow, Freyberger \& Grabe, 2006). These heterogeneous accepted uses of the concept of dissociation very probably masked over the pertinence of the first early descriptions of the extraordinary neuroses.

12 This historical recap has allowed us to take our bearings in relation to the category of "extraordinary neurosis". We do not intend to employ it as the "catch all" category which it became in a medicine that was stuck half way between magnetic healing and hypnotism, but we shall none the less conserve the base which consists of:

- hysterical neurosis with hallucinations and delusions (along with suggestibility, psychological automatism, and so on)

- a recourse to that which takes on the appearance of the paranormal.

\section{3 - Extraordinary Neurosis and Hystérie crépusculaire}

3 Back at the end of the nineteen seventies, Jean-Claude Maleval was working to revive the crepuscular (extraordinary) forms of hysteria (see Maleval, 1981; Libbrecht, 2001) in contradistinction to certain paradoxical clinical entities such as "hysterical psychosis". The "extraordinary" version of neurosis would professedly follow a pattern that is common to the "extraordinary" version of psychosis, even if it were not structured in the same way, as is underscored by the opposition between neurotic delirium and psychotic delusion (Maleval, 1981). None the less, the two can be brought closer together because, "in delusion, as is the case in delirium, the initial wavering of reality stands in relation to a shortcoming in its foundation; in both cases, the object has returned, closing up the gap of the cause of desire" (Maleval, 1981). In neurotic delirium, the subject becomes the prisoner of his imaginarisation, which is embodied in an anxiety provoking phallic presentification. "When the support of lack is itself wanting, the real object can surge up in the form of terror" (Maleval, 2011, p. 64). Extraordinary neurosis, in the sense that we understand it, seems to be "the best placed when it comes to revealing the defensive function of the fantasy: it is determined as being the pathology in which this defensive function finds itself being broached" (Maleval \& Sauvagnat, 1993, p. 17). The wavering of the barrier of the fantasy creates a space in which there is a sudden emergence of the avatars of the figure of the "vampire" that presents itself in waking nightmares and delirious states:

14

It is part and parcel of the [hysterical] structure that hysterical delirium should most often be focused on demoniac figures (vampires, incubi, succubae, influencing machines, extra terrestrials, and so on) which set about assaulting the subject, sometimes by trying to snatch from him the surplus jouissance that he harbors. They shape an image of the injunction of jouissance that reveals itself in the principle of the desire of the Other once the barrier of the fantasy starts to waver. In such a circumstance, it no longer appears to be apt to carry out its function in the service of pleasure, which consists in covering over the superego's requirement for jouissance.

(Maleval \& Sauvagnat, 1993, p. 17)

15 It is no small matter that, as an example of "the current condition of hysterical delirium", Maleval chooses (2011, pp. 96-107) to speak about experiences of kidnapping by extra terrestrials. [2][2]"In the absence of a structural approach to psychosis, and... Not only do these experiences draw in elements from the field of the paranormal, but the deployment of psychopathological discourses in this respect is anchored in the faults of the system of classification to be found in the Diagnostic and Statistical Manuals (DSM) (Evrard \& Le Maléfan, 2012).

16Therefore there exists a particular clinic of hysterical neurosis that presents itself as a fruitful alternative to the "psychoticisation" of hallucinatory and delusional experiences. This clinic meets up with other lines of research into forms of hallucination in which the underlying processes would not seem to be owing to a psychotic functioning either (Rabeyron, 2009). Nevertheless, it seems difficult to single out cases which would be proto typical of "extraordinary neurosis", perhaps because extraordinary neurosis would seem to be particularly sensitive to cultural tones and any relational patterns that have been established (for example, the couple formed by the hypnotizer and the hypnotized subject). The clinical study of extraordinary neurosis thus goes via these references to the first descriptions from the mid nineteenth century, to the cases of hysteria with hallucinations and delusions that were observed by Breuer and Freud (1895), by Janet (1889), and later by Maleval (1981), as well as passing via the contemporary clinic of "exceptional experiences" (Belz, 2009; Rabeyron, Chouvier, \& Le Maléfan, 2010) in which one common experience seems to be identified with each of these cases, because it is 
only after having specified what the elements particular to extraordinary neurosis would be that the clinical hypotheses in this regard could be put to the test.

\section{4 - "Welcome" Hallucinatory Aspects}

17In his studies on out of body experiences (Le Maléfan, 2011) and near death experiences (Le Maléfin, 2010), but also in his studies on apparitions (Le Maléfan, 2012; Le Maléfan \& Lemercier, 2012), Pascal Le Maléfan proposed a structural analysis inspired by the work of Lacan and by the work of Allouch (2011) on mourning. Instead of the traditional conception that has been drawn from one particular reading of Freud's article on "Mourning and Melancholia" (1917), the Lacanian conception reads death as a hole in the real to which the subject responds by projecting to this place the phallic signifier - the phallus that will be sacrificed and mourned in a second phase. This operation runs in the opposite direction of foreclosure, and therefore runs counter to a psychotic hallucination taken as a confrontation with a hole in the symbolic that reveals a structural fault (Allouch, 2011).

18 Le Maléfan draws on several observations of experiences of imminent death or out of body experience, in a clinic of trauma or post-trauma (for example, Roisin, 2009). In the experience of near death (Le Maléfan, 2010), the subject's experience would be a form of hallucinatory activity that would be "welcome" in the sense that it would support a reactivation of subjectivity in the midst of extreme critical situations in which both subjectivity and life itself run the risk of disappearing. These extreme situations are moments of wavering or piercing with respect to the fundamental fantasy that structures the subject. Some subjects will act through an elaboration that responds to the real that has intruded, but this is not the case for every subject, and it does not occur in the same way for every subject:

We are thus a long way from the archaic reflex that is mobilized afresh in cases of extreme danger, but rather in a situation of the unveiling of the fundamental fantasy of a given subject who comes to reveal his position with regard to a possible disappearance of any subjectivity. Thus, we are not equal faced with the sense of our impending death, depending on our personal history and what is known as "personality".

(Le Maléfan, 2012)

20Therefore, in relation to these experiences, inter individual differences persist, which also allow for a different understanding of the impressions of "transformation" that are among the most striking repercussions of such experiences (Greyson, 2000). The persistent memory of experience takes the form of a "new point of origin of the subject". According to Le Maléfan, it is not subjectivity that undergoes a modification, but the egoic agencies of the personality, in particular the Ideal Ego. These experiences would then come to rearrange the structure of certain subjects by passing via the register of the imaginary, as if the latter were effectively forming a supplementary device by bringing about subjective reorganizations.

21 On the basis of this structural analysis of several examples of "exceptional experience" in the academic literature (Belz, 2009; Rabeyron, 2009; Rabeyron, Chouvier \& Le Maléfan, 2010) for those structures that are not situated on the side of psychosis, one could generalize a typical process in extraordinary neuroses. Such a process would essentially be a matter of a wavering of the fundamental fantasy that structures the subject, a wavering that would be provoked, for example, by a hole in the real or by extreme situations in which the subject anticipates his own imminent disappearance. The hallucinatory aspect is summoned in order to shore up this rupture for the full time lapse during which the fantasy wavers, or for the entirety of the extraordinary state of the neurotic structure. In some subjects, and dependent on their subjective construction, this rupture will bring with it egoic rearrangements that establish a new relationship with desire. These kinds of productions have nothing automatic about them and remain derivatives of the manner in which desire (and thus the fantasy) has been constituted "on the basis of a founding sacrifice that has deprived the subject of the possibility of being the phallus, and a sacrifice of a part of himself that is forever veiled" (Le Maléfan, 2012). This process would be a welcome one because it would allow for a stabilization and a transformation of the fundamental fantasy that was wavering.

2 If this process seems to be verified in the course of certain transitory experiences that are induced by situations of rupture, it still remains to construct a theorization that will account for cases in which these experiences are more regular and in which they are tangled up in a life history that is more or less traumatic. This is where extraordinary neurosis can play a role as a more general description of a pattern of neurotic functioning in which the subject is swamped by percepts and cognitions that he does not integrate into his habitual model of 
reality in a general way. In the dreamlike, demonic, extra terrestrial or other figures that become present for him, he might find some support by which to rearrange his fantasy and reorganize himself in a way that is more compatible with his social environment, or else his new surroundings in which his oddity will be welcomed as being more "ordinary". This can go in the direction of sects, and more insidiously still, groups that bring together people who are supposed to have shared the same "extraordinary" experiences and which campaign to change hearts and minds. Indeed, is it not part and parcel of the logic of hysterical delirium to find refuge in campaigning for a cause? (Maleval, 2011)

\section{5 - Conclusion}

3 The classical opposition between neurosis and psychosis - the opposition that constitutes the "binary clinic" that is falsely attributed to the psychoanalytic clinic (Miller, 2009) - in our view conceals more complex lines of opposition. The return to favor of the category of extraordinary neurosis and the acknowledgement of ordinary psychosis allow a structural nosology to be constituted that is comprised of four terms: ordinary neurosis (ON), extraordinary neurosis $(\mathrm{ExN})$, ordinary psychosis $(\mathrm{OP})$ and extraordinary psychosis (ExP).

4 Between the neuroses and the psychoses, a categorical distinction stands to be drawn in accordance with the mode of organization of the structure - hence the different research projects that have made differential criteria more positive by exposing this structural limit on the basis of Lacanian theories of psychosis (Maleval, 1981, 2011).

25 Furthermore, at the heart of each structure there would be a continuum that reaches from an "ordinary" pattern of functioning to an "extraordinary" pattern. We have striven to make this continuum correspond to the one that is typified by the recourse to hallucination and to delusion. Since these experiences are not specific to a structure, even though they remain associated with psychosis in people's minds, the label "exceptional experiences" effectively enables us to account both for the place they have for the subject and for how they are frequently interpreted in terms of the paranormal (Rabeyron, 2009). The following diagram (Figure 1) illustrates these ideas.

26Despite the reductionism that is endemic to any schematisation, we would like to promote this hypothesis of an "ordinary neurosis" that according to us is able to account for certain data [3][3] In their important systematic review of the literature on...; and of orienting clinical practice towards a differential structural clinic that sets its sights on the promotion of an ordinary modality of structural functioning (either ON or OP) that would replace the extraordinary modality (either ExN or ExP, respectively). Nevertheless, other clinical examples, to be analyzed or re-analyzed according to this hypothesis, are still necessary to support it more rigorously.

27 Might not the structural orientation that we have set out here come to fall into the camp of those paradoxes that have led some authors to speak of "hysterical psychosis"? (De Luca, 2009)

28 In hunting out "structure" in the "states" that the subject passes through, one runs the risk of freezing its movement in diagnostic presuppositions. A clinic of processes - which draws for example on the "welcome" hallucinatory aspect that has been brought to the fore by Le Maléfan - could very well sketch out clinical lines of approach that will deal with the "extra ordinary" items that the patient mentions, while breaking loose from the effects that this diagnosis carries with it. Does not our work with hallucinations and delusions incite us to make the unthinkable thinkable (Gimenez, 2010)? But this only seems to be possible by getting past the unease, which historically and epistemologically is well anchored in the psychoanalytic field (Evrard \& Rabeyron, 2012) despite high quality work that has already been published for some time now (Devereux, 1953), with respect to the clinician's relationship with this material that seems to be in favor of the most commonly accepted reality.

\section{Notes}

- $[1]$

Doctor Motet (1861) was none the less to be allowed to present a further case of "extraordinary neurosis" during the session of 27 February 1860, which in all likelihood was a case of serious hysteria with no access to lucidity. 
- $[2]$

"In the absence of a structural approach to psychosis, and without any rigorous grasp of hysteria, indeed in the absence of any clear cut distinction between delusion and delirium, the accounts of kidnapping by extra terrestrials, along with other fabulations, would be qualified by some as delusions and the subjects would be treated as though they were psychotic. When the clinic of major hysteria is misrecognised, false accusations can wreak great havoc, in particular when they have to do with sexual abuse suffered in childhood, provoked by fantasizing that gets the upper hand over the subject's conviction, and sometimes that of the judges too.” (Maleval, 2011, p. 107)

- [3]

In their important systematic review of the literature on experiences reputed to be "psychotic" in the general population, Linscott \& van Os (2010, p. 23) conclude that the continuum in the expression of the phenotype of schizophrenia is underwritten by two different sub populations. In other words, if one observes carefully the presence of hallucinatory and delusional experiences in the general population, such experiences could, according to one interpretation of psychoanalytic psychotherapy (Evrard, 2011) be developed either against the backdrop of a neurotic structure of against the backdrop of a psychotic structure. 